В ходе исследований и коллегиальной работы формируется состав внешних и внутренних факторов, способных оказать влияние на уровень рисков. Для оценки риска применяются в совокупности методы сценарного анализа и ранжирования. Выявленные угрозы, сведённые в единую таблицу, представляющую собой систему факторов риска, позволяют идентифицировать значимые риски, выявить их качественные и количественные характеристики: вероятность проявления, размер потенциального ущерба, место возникновения, уровень взаимосвязей между факторами и т.п. Каждая компания сама устанавливает понятие опасности и единицы ее измерения. Для менеджмента в ряде случаев под ней понимается упущенная прибыль, для остальных - доход.

Проведённая работа позволяет выделить группу рисков, являющихся реально опасными, по ним необходимо разработать план немедленных (первоочередных) мероприятий, по группе допустимых рисков требуется разработка плана годовых мероприятий, а в отношении маловероятных - необходимо создать план контролируемых мероприятий для того, чтобы со временем они не перешли в разряд допустимых или даже опасных.

Представленный механизм объединяет в себе несколько подходов к оценке и анализу рисков, поэтому его основным достоинством является то, что он может использоваться в случае, когда у менеджмента отсутствует полная информация об анализируемых факторах и часть оценок выполняется экспертами на качественном уровне. Для корректного использования этого механизма необходимы внутренние стандарты и процедуры, обучение менеджмента и сотрудников, вовлекаемых в процесс, постоянный надзор за качеством проводимой оценки.

$$
* * *
$$

1. Изварина Н.Ю., Квон Н.С. Значение налогового риск-менеджмента в системе управления рисками компании // Научный диалог: Молодой ученый. Сборник научных трудов, по материалам XIV международной научно-практической конференции 22 февраля 2018 г. Изд. ЦНК МОАН, 2018. 68c. (c. 38-41)

2. Кудрявцев А.А.: Интегрированный риск-менеджмент: Учебник / А.А. Кудрявцев; СПбГУ, экон. факультет. - М.: ЗАО «Издательство «Экономика», 2017. - 655c.

3. Лесных В.В. Методика интегральной оценки рисковых событий по качественно и количественно заданным факторам / В.В. Лесных // Управление риском. - 2016. - № 2. - С. 67-72

\title{
Ильяшенко В.В. \\ Взаимосвязь денежных доходов населения и уровня инфляции в российской экономике
}

Уральский государственный экономический университет (Россия, Екатеринбург)

doi:10.18411/spc-08-04-2018-09

idsp: 000001:spc-08-04-2018-09

Увеличение денежных доходов населения в экономической литературе рассматривается в качестве одной из причин инфляции спроса. Это связано с ростом потребительских расходов как составной части совокупного спроса. Кроме этого, повышение заработной платы может влиять и на развитие инфляции издержек, поскольку заработная плата включается в себестоимость продукции и определяет расходы предприятия на производство продукции.

Однако в полной мере рост денежных доходов населения может быть причиной развития инфляции спроса при условии полной занятости факторов производства или высокого уровня использования производственных мощностей. Однако в экономике России уровень загрузки производственных мощностей в производстве машин и оборудования, электрооборудования, электронного и оптического оборудования, 
транспортных средств и оборудования в 2016 г. в РФ, по данным Росстата, не превышал 53\%; в текстильном и швейном производстве - 64\%; в производстве пищевых продуктов (за исключением мяса и сахара) - 64\%. Хотя некоторые авторы (Мау В., Кудрин А., Горюнов Е., Трунин П.), несмотря на данные официальной статистки, утверждают, что в современной России существует высокий уровень загрузки производственных мощностей и выпуск продукции близок к потенциальным возможностям экономики.

Подобная позиция влияет на формирование государственной экономической политики, направленной на преодоление инфляции монетаристскими методами, направленными на уменьшение денежного предложения и существенное сокращение совокупного спроса. Как отмечал один из основоположников монетаристской теории М. Фридмен: «Инфляция всегда и везде представляет собой денежное явление, возникающее и сопровождаемое более быстрым ростом денежной массы по сравнению с объемом производства». Очевидно, что можно добиться снижения уровня инфляции, если рассматривать борьбу с инфляцией как самоцель, принимая меры, направленные на сокращение совокупного спроса путем снижения реальных доходов населения, инвестиционных и государственные расходов. Так, благодаря именно этим мерам Правительство РФ и Банк России добились снижения уровня инфляции в России в 2016 г. до 5,4\%, а в 2017 г. до 2,5\%. Однако при этом экономика страны в последние годы находилась в депрессивном состоянии. Физический объем ВВП снизился на 2,5\% в 2015 г. и на $0,2 \%$ в 2016 г. Некоторый экономический рост произошел в 2017 г. (прирост физического объема ВВП составил 1,5\%), чему во многом способствовали снижение ключевой ставки процента Центральным Банком и существенное повышение мировых цен на нефть (цена нефти марки BRENT в январе 2016 г. составляла 30,8 долл. за баррель, а вянваре 2018 г. превысила 69 долл. за баррель). По данным Росстата, индекс инвестиций в основной капитал снизился со 106,8\% в 2012 г. до 89,9\% в 2015 г., в 2016 г. составил 99,8\% по сравнению с предыдущим годом.

Вместе с тем анализ данных Росстата свидетельствуют о неоднозначной зависимости между увеличением номинальных денежных доходов населения и повышением темпов инфляции. На протяжении последних 20 лет среднедушевые доходы населения, номинальная начисленная заработная плата и средний размер назначенных пенсий ежегодно увеличивались. Однако темп инфляции при этом изменялся как в сторону повышения, так и в сторону снижения. Более того, в основном преобладали периоды, когда при значительном изменении денежных доходов уровень инфляции менялся в противоположном направлении. Например, в 1998 г. существенно снизился прирост среднедушевых доходов населения и среднемесячной номинальной начисленной заработной платой по сравнению с предыдущим годом (соответственно с $22,2 \%$ до 7,4\% и с 20,2\% до 10,6\%), но темп инфляции значительно повысился (с $11,0 \%$ до 84,4\%). В 1999 г. произошли противоположные изменения: прирост среднедушевых доходов населения и среднемесячной номинальной начисленной заработной платой по сравнению с предыдущим годом существенно повысились (соответственно с 7,4\% до $64,2 \%$ и с $10,6 \%$ до 44,9\%) при очень значительном уменьшении уровня инфляции (с $84,4 \%$ до $36,5 \%$ ). Высокие темпы прироста среднедушевых доходов населения, среднемесячной номинальной начисленной заработной платы и среднего размера назначенных пенсий наблюдались в 2000-2006 гг. при ежегодном снижении уровня инфляции. Заметим, что именно в этот период осуществлялась государственная политика не сдерживания, а напротив, стимулирования совокупного спроса. Она проявлялась не только в значительном увеличении номинальных и реальных доходов населения, но и в существенном ежегодном приросте инвестиций в основной капитал. В 2008, 2010 и 2014 гг. изменение денежных доходов населения России и уровень инфляции также изменялись в противоположных направлениях. 
По мнению автора, в современных условиях именно стимулирование совокупного спроса, в том числе через повышение денежных доходов населения России, может позитивно повлиять на увеличение степени использования производственных мощностей и развитие национального производства, что, в свою очередь, будет способствовать увеличению совокупного предложения продукции и снижению средних издержек. Это имеет важное значение для снижения темпа инфляции издержек, так как преобладающую роль в российской экономике, как показали наши исследования, играет именно данный тип инфляции, обусловленный действием не монетарных, а затратных факторов. Преодоление инфляции популярными в современной России монетаристскими методами в условиях неполной загрузки производственных мощностей может обеспечить только кратковременный эффект при замедлении или снижении темпов экономического развития, сокращении инвестиций и реальных доходов или, в лучшем случае, крайне низких темпов их прироста, не оказывающих принципиального влияния на развитие и техническое обновление российской экономики, проведение неоиндустриализации. Очередное относительно существенное снижение мировых цен на нефть в условиях сохранения экспортносырьевой ориентации экономики России приведет к девальвации рубля и неизбежному повышению уровня инфляции.

Для стимулирования совокупного спроса целесообразно снижение ключевой ставки ЦБ до уровня, близкого к темпу инфляции; освобождение от налога на прибыль средств, использованных на инвестиции и инновации; повышение эффективности антимонопольного законодательства; введение прогрессивной шкалы налога на доходы физических лиц с освобождением от уплаты налога низкооплачиваемых групп населения; принятие эффективных мер для ограничения вывоза капитала за границу и др. Важными мерами станут также принятые решения о повышении минимальной заработной до уровня прожиточного минимума и заработной платы работников бюджетной сферы в 2018 г.

$$
* * *
$$

1. Ильяшенко В.В. Методология анализа инфляции в курсе экономической теории // Журнал экономической теории. 2013, № 3.

C. $38-47$.

2. Ильяшенко В.В., Куклина Л.Н. Инфляция в современной России: теоретические основы, особенности проявления и региональный аспект // Экономика региона. 2017 г. Том 13 (вып. 2). С. 434-445.

3. Кудрин А., Горюнов Е., Трунин П. Стимулирующая денежно-кредитная политика: мифы и реальность // Вопросы экономики. 2017, № 5. C.5-28.

4. Мау В. Антикризисные меры или структурные реформы: экономическая политика России в 2015 году // Вопросы экономики. 2016, № 2. С.5-33.

5. Фридмен М. Если бы деньги заговорили ... - М.: Дело, 1999. - 157 с.

\section{Коденко И.А., Щеглова Ю.А., Яковлева Г.Ф. \\ Информационные таможенные технологии как индикатор развития внешнеторговой деятельности Российской Федерации}

Белгородский университет кооперации, экономики и права (Россия, Белгород)

doi:10.18411/spc-08-04-2018-10

idsp: 000001:spc-08-04-2018-10

\section{Аннотация}

Членство Российской Федерации во Всемирной таможенной организации, формирование Единого экономического пространства обусловили необходимость существенной модернизации таможенного администрирования, которая невозможна без внедрения в работу таможенных органов перспективных информационных технологий, соответствующих требованиям Международной конвенции об упрощении 